IRA-International Journal of Management \&

Social Sciences

ISSN 2455-2267; Vol.16, Issue 03 (July-Sep. 2020)

Pg. no. 113-120.

Institute of Research Advances

http://research-advances.org/index.php/RAJMSS

\title{
Relevance of Curriculum, Instruction, and Facilities to Knowledge, Skills, and Abilities of Masters in Business Administration Program Graduates of Nueva Ecija University of Science and Technology in the Philippines
}

\author{
CUYA, Thamar M. ${ }^{1}$, DAYRIT, Amayna Shaene $C^{2}{ }^{2}$, CUYA-ANTONIO, Olive Chester M. ${ }^{3 \#}$, \\ PASCUAL, Marilou P. ${ }^{4}, \&$ FRONDA, Jennifer G. ${ }^{5}$ \\ ${ }^{1,2,4.5}$ Graduate School, Nueva Ecija University of Science and Technology, Philippines. \\ ${ }^{3}$ College of Public Administration and Disaster Management, Nueva Ecija University of Science \\ and Technology, Philippines.
}

\# corresponding author

Type of Work: Peer Reviewed.

DOI: http://dx.doi.org/10.21013/jmss.v16.n3.p6

How to cite this paper:
CUYA, Thamar M. et al. (2020). Relevance of Curriculum, Instruction, and Facilities to Knowledge, Skills,
and Abilities of Masters in Business Administration Program Graduates of Nueva Ecija University of
Science and Technology in the Philippines. IRA-International Journal of Management \& Social Sciences
(ISSN 2455-2267), 16(3), 113-120. doi:http://dx.doi.org/10.21013/jmss.v16.n3.p6

(C) Institute of Research Advances.

This work is licensed under a Creative Commons Attribution-NonCommercial 4.0 International License subject to a proper citation to the publication source of the work.

Disclaimer: The scholarly papers as reviewed and published by the Institute of Research Advances (IRA) are the views and opinions of their respective authors and are not the views or opinions of the IRA. The IRA disclaims of any harm or loss caused due to the published content to any party.

Institute of Research Advances is an institutional publisher member of Publishers International Linking Association Inc. (PILA-CrossRef), USA. The institute is an institutional signatory to the Budapest Open Access Initiative. Hungary advocating the open-access of scientific and scholarly knowledge. The Institute is a registered content provider under Open Access Initiative Protocol for Metadata Harvesting (OAI-PMH).

The journal is indexed \& included in WorldCat Discovery Service (USA), CrossRef Metadata Search (USA), WorldCat (USA), OCLC (USA), Open J-Gate (India), EZB (Germany) Scilit (Switzerland), Airiti (China), Bielefeld Academic Search Engine (BASE) of Bielefeld University, Germany, PKP Index of Simon Fraser University, Canada. 


\begin{abstract}
Graduate education plays a significant role in the development and the economy of the nation. Therefore, it is significant to evaluate the program it offers as they provide relevant contributions to their graduates' knowledge, skills, and ability in the workplace. This study explored the relevance of curriculum, instruction, and facilities of the Master in Business Administration program (MBA) at the Nueva Ecija University of Science and Technology (NEUST) to the knowledge, skills, and abilities of the graduates. Guided by Active Learning Theory, the study utilized a qualitative research design to understand the meaning and actual experience of the participants in their natural work settings. The emerging themes and recurring patterns from the interview and field notes are presented, discussed, and supported by the actual data and existing studies. The analysis showed that the curriculum, instruction, and facilities are relevant to their acquired knowledge, skills, and abilities, which are significant to their workplace. Furthermore, the university's approach of providing actual work environment experience coupled with instructors who are experts in the field provides the relevant learning experience for the graduates. The least relevant and the least rating was given to the facilities. For the graduate education to be relevant, it needs to cope with the constantly changing and developing environment. It needs continuous enhancement and it can be done through the evaluation and feedbacks of the graduates. Future researchers might consider a more comprehensive evaluation of the graduates' experience both quantitatively and qualitatively for future study.
\end{abstract}

Keywords: active learning, Masters in Business Administration, relevance of curriculum.

\title{
INTRODUCTION
}

Graduate studies play a vital role in developing ideas, production, man-power, research, and in-depth analysis of different fields. Through its knowledge-etching instructions and its research-based education, they are able to provide the students with knowledge, skills, and abilities to cope with the ever changing technology and environment. As work environment becomes competitive, academic institution must not be limited to conveying knowledge to its students, but also in developing real time professional experiences grounded on principles and foundations. It influences the students to be competent and professional in their workplace applying theories and practices that they have acquired in their advanced learning education.

Several studies noted that learning is always a significant part of educational process. It seeks to develop and strengthen the knowledge, skills and values of every learner [1]. In the current employment situation, company values skills, knowledge and abilities and it is reflected on the individual's employability and salary. Individual's skills, knowledge and abilities are mostly developed through education and experience. According to [2], there is a positive correlation between education levels and salaries. The higher is the education level achieved, the higher is the earnings of an individual. It implies that the more individuals pursue higher and advanced education the most likely they would attain higher income.

It is therefore a good standpoint to evaluate the graduates of an academic graduate program by analyzing the institution's curriculum, faculty, and facilities and its relevance to skills, knowledge, and abilities of the graduates. Findings from the study of [3] showed that the skills and knowledge of the students are influenced by the quality of curriculum. The quality of curriculum includes the instructional practices and strategies, and the curriculum design and content. When students are engaged in the curriculum, it influences their mastery of the content and their skills as well [3]. In general, the environment of the students, the quality of instruction, and the approach of the institution influence their learning and skills [4]. These factors help shape, equip, and empower the graduates to excel in their respective field [5].

Advanced or graduate education is an active means to strengthen research skills and potentials of professionals in theory and in practice [6]. [6] cited the statement from The Commission on the Future of Graduate Education (2010) that the challenges currently faced by the countries in the world depend on the quality of professionals with graduate level education. It is considered that professionals with graduate education degrees can contribute to the nation's economic development. Thus, countries, like China and India, invest on developing human capital by sending their citizens to other countries' graduate school programs [6]. 
In the Philippines, one of the most sought graduate programs is the Master in Business Administration (MBA). Having an MBA qualification is seen as a passport for a managerial role [7]. In securing job in highly competitive global marketplace, a master's degree sets an applicant apart from other job candidates. A master's degree qualifies an applicant for more jobs particularly in managerial position [8]. In the current situation of the country, the business sector plays a vital role in the economy. Therefore it is timely to assess the quality of MBA graduates for they can provide significant contributions in the country's development.

This study examines the relevance of the curriculum, instruction, and facilities to the knowledge, skills, and abilities of MBA graduates of Nueva Ecija University of Science and Technology (NEUST). It explores how the MBA graduates consider the influence of the curriculum design; the faculty's teaching strategies; and the university facilities to strengthen their knowledge, skills, and abilities in their workplace. Specifically, the study answered the following questions: a) What are the knowledge, skills, and abilities that the students have developed upon taking the MBA program at NEUST?; b) What is the relevance of the program curriculum on the graduates' knowledge, skills, and abilities as applied in their workplace?; b) What is the relevance of the instruction in enhancing the knowledge, skills, and abilities of the MBA graduates?; c) What is the relevance of the school facilities in the development of the knowledge, skills, and abilities of the MBA graduates?; and d) What possible recommendations may be offered to enhance the knowledge, skills, and abilities of MBA program graduates?

Understanding the relevance of the factors used in this study would contribute to the few available resources on graduate program studies. Most of the existing studies are tracer studies on college graduates and their employment status, but few literatures are provided on graduates of advanced education and its influence on their work performance. With the increasing number of professionals being favored in employee selection and promotion due to their level of education, this study would provide data to understand how the graduate education shapes the students to be effective managers which exhibit vital impact on the organization and the country's productivity.

\section{Theoretical Framework}

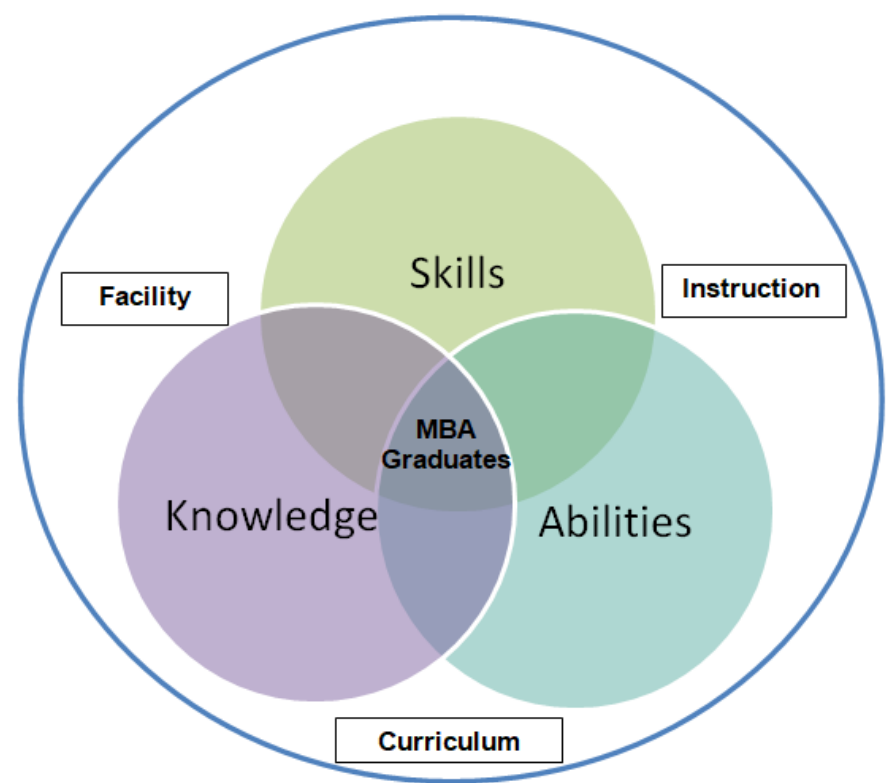

Figure 1. Concept map of the relevance of curriculum, instruction, and facility on the knowledge, skills, and abilities of MBA graduates

Teaching and learning process nowadays lean to the application of theories into practices, particularly in graduate education. This is the focus of the Active Learning theory of education which is based on constructivism $[9,10]$. There are several descriptions of Active Learning theory as they are based on several educational theorists who believe in a learner-centered approach in the education process. Students 
learn by discovering it on their own through the guidance of the facilitator of learning and the school environment and activities [10]. The students are encouraged to think critically, reflect, and engage that would increase their knowledge, skills, and abilities in different disciplines. Therefore the learners are able to generate learning based on a theoretical foundation and apply it into their workplace which is the case in the graduate education programs. Presented in Figure 1 is the concept map used in the study.

The figure depicts the relevance of the curriculum, instruction, and facility on the knowledge, skills, and abilities of MBA graduates as used in the study. In the lenses of the Active Learning theory, the MBA graduates developed their learning through the curriculum design, teaching methods of the faculty, and the environment of the school. The learning that the graduates generated from the school will then shape them on how to perform in their workplace. Therefore the quality of the graduate school's curriculum, instruction, and facilities influences the quality of graduates that the school produces.

\section{METHODOLOGY}

\section{Research Design}

The study analyses the relevance of the curriculum, instruction, and facilities to the knowledge, skills, and abilities of MBA graduates by examining the participants' perceptions, and performance at their workplace. Using the qualitative research methods the authors utilize interviews, participant observation, and document analysis to understand and describe the different factors considered in the study. Furthermore, the research tools used were to provide validation and confirmation of the findings and it's consistency with other existing studies.

Qualitative design was used as it is designed to understand the phenomena. As cited by [11, 12] defined the goal of qualitative approach to research as "describes and analyses the world as it is experienced, interpreted and understood by people in the course of their everyday lives" [11,12]. Moreover, there are several quantitative studies conducted on the same scope but very few have tried to confirm the findings on the ground. Qualitative approach is suitable in this study as it provides "deeper meaning to the lived experiences" of the participants on their natural settings [13].

To avoid personal bias, member checks were utilized during and after interviews, thus increasing credibility, validity, and transferability of the findings [14].

\section{Study Locale}

The NEUST caters students coming from the different parts of Central Luzon, which is the largest major island in the Philippines. However majority of its students reside within the province of Nueva Ecija. Nueva Ecija is known to be the rice granary of the Philippines because of its rich agricultural products and its main produce is the palay which is an important staple crop of the country. Due to its location it serves as the gateway of Southern Luzon and Northern Luzon, thus, paved the way for increase in investments and business economy. With its vibrant economic growth and beautiful tourist spots, it is potential to be an economic hub in the country.

One of the leading universities in Nueva Ecija is the Nueva Ecija University of Science and Technology (NEUST), formerly known as Central Luzon Polytechnic College (CLPC). It is known for its quality education due to its performance in board courses specifically in engineering and education. Currently, it offers a wide variety of programs from undergraduate to graduate studies. Among the most sought programs in the university when it comes to college and master's degree is the Business Administration. Therefore the study would provide significant analysis of the university's performance in terms of the quality of its curriculum and instructors, as well as the quality of its graduates, particularly in the graduate program.

\section{Participant Selection}

To choose qualified participants, the researchers resorted to purposive sampling. This sampling method is highly relevant, for the selection of the participants would contribute to a better understanding of the study [15]. The following criteria were used to qualify the participants: (a) A graduate of NEUST Master in 
Business Administration (MBA) from different academic years; (b) currently employed on a full time basis; and (c) has managerial or supervisory role. Considering the distinct quality and the number of graduates that fit into the criteria, the researchers recruited the four MBA Graduates. The participants graduated from the university in 1998, 2002, 2016, and 2020 which provides a good range to establish the consistency of the program curriculum. The four participants range from 28 to 55 years of age and two of them are in a supervisory position, while one is a bank manager, and the last one is a vice president for operations; two are female and two are male.

Though the number of participants is less, the data gathered is enough to reach saturation by providing adequate data to answer the research questions. Further data collection and analysis are, therefore, unnecessary [16].

\section{Data Collection}

\section{Interview process}

The four participants were interviewed to determine their occupational classification and perceptions on how relevant the curriculum, faculty, and facilities were to their knowledge, skills, and abilities. An interview guide with close-ended and open-ended questions was devised to answer the research problems. The questions were divided into parts; the first gather the profile of the respondents, while the remaining gathers the relevance of the curriculum, of instruction, and the facilities of MBA Program at NEUST. The researchers scheduled the interview based on the availability of the participants. During and after the interview, the researchers restated and summarized the gathered information and confirmed the contents from the participants for accuracy.

\section{Participant observation}

During data-gathering and participants' interviews, field notes were also collected as the researchers observe the participants and their work performance and environments. Particularly, the participants' interaction with their co-workers, staff, and clients were considered. This process aims to describe the characteristics of the participants in their workplace that can support the data being gathered. Data collected from the interview and the field notes were compared to identify the emerging themes that answered the research questions.

\section{Confidentiality of data}

The confidentiality of the data gathered was assured to the participants. During the data-gathering, informed consent was obtained from all of the respondents. They are well-informed of the purpose of the study and their rights to withdraw, and they all agreed to participate in the study. All personal and work information and accounts of the participants are protected and treated with confidentiality by preserving their anonymity. The researchers used coding to hide the identity of the participants.

\section{Data Analysis}

Analysis of the data gathered occurred in the following: a) the interview transcripts were reviewed and analyzed for "recurring regularities" [17], the researchers noted the emerging themes and coded them; b) then, the coded interview and field notes were analyzed together by looking for relationships within and across the data sources and creating a table; c) last, the categories are refined to solidify the themes.

\section{RESULTS AND DISCUSSIONS}

\section{Knowledge, Skills, and Abilities of the MBA Graduates}

Since the participants have a different experience in the university during their graduate studies, their gained knowledge, skills and abilities (KSA) will be a good point for comparison. The results of the process show that the emergent themes were "management", "leadership," and "supervision". All of the participants considered that they have gained the KSA on management or managerial skills which are also 
supported by their current employment status. Occupational classification is one of the factors that ascertain the effectiveness of the knowledge acquired in an academic institution. Through their professional experience it can easily be assured that they have learned a lot about management. It is the core competency that MBA program aims to develop to their students and it concurs to the study of [18]. Their acquired management or managerial skills equipped them to be competent in their workplace and in the business industry. Participant P3 also shows that their acquired KSA in their study of the program gave the confidence to set up their own line of business. This skill is the actual application of their learning in the program. Not to mention the participants all have a supervisory and managerial positions which affirm their management skills.

The KSA of the participants on "leadership and supervision" is obvious to their current positions in the company. However leadership skill goes beyond position. It is the ability of a person to influence others in the accomplishment of a desired goals and objectives [19]. As observed in the participants' working environment and performance, majority of them showed an evident leadership skill through their way of communication with their co-workers, subordinates, and clients. They showed confidence in handling things and provide directives to the people around them.

Meanwhile, their supervisory skills are not fully observed by the researchers at the ground since the participants are mostly in their offices and giving orders. However, participants P1 and P2 have a long experience in supervisory and managerial position which implies that they earned it to be in the position for a significant time, thus most likely they showed good supervisory skills. Likewise, supervisory skills may also manifest through their managerial skills as managerial skills not only means management of business but also of personnel in the organization.

\section{Relevance of the Program Curriculum on the Knowledge, Skills, and Abilities of the MBA Graduates as Applied in their Workplace}

The curriculum has significant influence to the KSA of the students. It dictates how the student will experience learning in the institution and what KSA should the learners develop. As shown by the interview results, the participants gave a high rating of the relevance of MBA program curriculum on their KSA as it is applied in their workplace. Though they graduated from different school years, their responses are almost the same. The learning experiences that the program provides are "relevant" and "applicable" to their workplaces. For the teachings are not only based on theories but on the actual application in the field. According to participant P3,

"Yung NEUST kasi... pumupunta sila sa mga different businesses during your MBA studies. Pinapakita talaga nila yung different aspects ng business, so pina pa-experience nila sa inyo kung ano yung mismong nasa market environment. So hindi lang siya puro theories, more on application of the theories na pinag-aaralan." [The NEUST brings the students to different business industries during the MBA studies. They show the different aspects of businesses, and provide the actual learning experience in the workplace and market environment. It is not just about theories, but more on application of theories being taught.]

The responses reflect the satisfaction of the graduates on the program and the university. It also confirms the findings of [18] that students choose the University due to its reputation in providing competitive education. In the case of graduate education the relevance of the curriculum is vital, and it can only be evaluated through the feedbacks of the graduates. Providing a different learning experience to the students through actual experiences and based on theoretical foundations increases its relevance and responsiveness to the community development. It will be evident to the competencies or the KSA acquired by the graduates and validated also by them.

\section{Relevance of the Instruction in Enhancing the Knowledge, Skills, and Abilities of the MBA graduates}

Teachers are the facilitators of learning. They are the one who give the students the experience to learn and engage in the curriculum [3]. Based on the interview, the participants are convinced that NEUST provides 
the "best", "quality", "knowledgeable", "credible", and "highly competent" faculty in the MBA program. These are the recurring themes mentioned by the participants that prove the quality of instruction in the university. The program provides not only teachers from the university but experts in the field of Business Administration, and it increases the relevance of instruction which according to the participants enhances their KSA. Moreover, the specialization of the instructors injects the learning experience that the students need to enhance their KSA. And the participants only have positive feedbacks regarding the quality of instruction due to this best practice of the university.

\section{Relevance of the School Facilities in the Development of the Knowledge, Skills, and Abilities of the MBA graduates}

In the evaluation of the relevance of the school facilities in the development of KSA of the graduates, the matter of different school years are again evident. Because technology and development is apparent in the changing years, the education sectors need to adapt to the changes for it to be relevant.

Based on the participants' answers, the emerging themes are "okay", "conducive", and "needs improvement". It is glaring that the answers indicate the participants' assessment of the school facilities and not on the relevance of the facilities in the development of their KSA. While the response did not directly answer the questions, the participants explained the need for improvement of the facilities. The environment is conducive to their learning and the facilities have improved compared to the previous years but it still needs improvement.

According to participant $\mathrm{P} 4$, "Yung facilities, ok naman conducive, yung number ng students nila is kakaunti, kakaunti in a sense na madaling na gra-grasp ng mga students or MBA students, yung mga tinuturo sa kanila naa-absorve....kung baga distributed yung part na nai-impart na knowledge sa amin." [Yes, facilities are okay, it is conducive since there is small class size. Students absorb the teaching well, and the imparted knowledge is distributed among the students.] Meanwhile, participant P2 answered, "Physical facilities? A lot of...more improved now than before. From the time I was taking up my Master, a lot have improved since then in terms of facilities....in a scale of 5 and 5 being the highest, I can say 4, there's a need for a room for improvement."

In general, based on the participants' response, the facilities also contribute to their learning in the university. The more conducive the environment is, the more it will encourage them to learn. It is also glaring that among the parameters used it is the "Facilities" that has been given the least credit. Though there are improvements in the facilities of the university, the graduates still wish for more enhancements especially in the graduate school programs.

\section{CONCLUSIONS AND RECOMMENDATIONS}

An engaging curriculum is the one that allows its students to think critically, reflect, and experience learning. It is through this that learners are able to generate knowledge, skills, and abilities (KSA) that they can apply in their workplace. This process is essential for graduate education for students are either already employed or are seeking for employment. Thus, the knowledge, skills, and abilities they acquire in advanced education will prepare them for the actual work they are going to pursue. Moreover, graduate students are the workforce of the nation and their performance in the workplace provides significant contribution to the country's economy.

Based on the findings, the curriculum, instruction, and facilities are relevant in the acquired knowledge, skills, and abilities of the graduates. Their experience on how the subjects are taught, the competence of the teachers, and their learning environment really contributes to their KSA, which are significant to their workplace. The best practice of the university that has been very helpful to the graduates is the actual work experience that the curriculum provides. This experience coupled with instructors that are experts in the field of Business Administration make the program highly relevant to MBA students. Meanwhile the least rating of the participants are given to the facilities as it is also provides the least relevance to their acquired KSA. 
For the graduate education to be relevant, it needs to cope with the constantly changing and developing community. It needs to enhance its curriculum, instruction, and facilities to continue providing quality education. Moreover, feedback from the graduates would provide significant evaluation of the program. Hence, for further study, future researchers might consider a more comprehensive evaluation of the graduates' experience both quantitatively and qualitatively.

\section{References}

[1]. Macalalad, J.A., Buenviaje, M.G., Regalario, G.M., and Laguador, J.M. (2016). Employment Status of Graduates in Post Baccalaureate Degree in Business Administration of one Higher Education Institution in the Philippines, Asia Pacific Journal of Education, Arts and Sciences, 3 (4),17-26

[2]. Carlson, R.H. \& McChesney, C.S. (2015). Income Sustainability through Educational Attainment. Journal of Education and Training Studies, 3 (1), 108-115, Redfame Publishing, doi:10.11114/jets.v3i1.508

[3]. Luciano, J. (2014), "The Influence of Curriculum Quality on Student Achievement on the New Jersey Assessment of Skills and Knowledge (NJ ASK) Language Arts and Mathematics for Fifth-Grade Students in the Lowest Socioeconomic School Districts".

[4]. Rugutt, J. K. \& Chemosit, C. C. (2005). A Study of Factors that Influence College Academic Achievement: A Structural Equation Modeling Approach. Journal of Educational Research \& Policy Studies, Spring 2005, $5(1), 66-90$

[5]. Encio, H. A., Refozar, R. F. G. \& Laguador, J. M. (2018). Impact of Master in Business Administration Program to its Graduates' Job Performance. Asia Pacific Journal of Academic Research in Social Sciences, Vol. 3, 51-60

[6]. Bueno, D. C. (2017). Ascertaining the Curriculum Relevance of the Graduate School through Tracer Study in a Philippine Private Higher Education Institution. JPAIR Multidisciplinary Research, 28, pp. 72-88, https://doi.org/10.7719/jpair.v28i1.502

[7]. Ramlall, S.J. \& Ramlall, D.P. (2016). An effective MBA: Perspectives of Students, Faculties, and Employers. Journal of Management and Strategy, 7 (3), 18-22, doi:10.5430/jms.v7n3p18

[8]. Felicen, S.S. \& Ylagan, A.P. (2018). Tracer Study of Master in International Hospitality Management for 2010-2015. Asia Pacific Journal of Education, Arts and Sciences, 5 (1),88-97

[9]. Hartikainen, S., Rintala, H., Pylväs, L. \& Nokelainen, P. (2019). The Concept of Active Learning and the Measurement of Learning Outcomes: A Review of Research in Engineering Higher Education. Education Sciences, 9 (276), pp. 1-19, doi:10.3390/educsci9040276

[10].Cattaneo, K. H. (2017). Telling Active Learning Pedagogies Apart: from theory to practice. Journal of New Approaches in Educational Research. 6 (2), pp 144-152, DOI: 10.7821/naer.2017.7.237

[11].Cropley, A. J. (2019, 2nd updated, revised, and enlarged edition). Qualitative research methods: A practiceoriented introduction for students of psychology and education. Riga, Latvia: Zinātne. (open access - doi: 10.13140/RG.2.1.3095.6888)

[12].Hollis, M. (1994). The philosophy of social science. Cambridge, UK: Cambridge University Press.

[13]. Arneil G. Gabriel \& Gloria M. Alcantara \& Josephina D. G. Alvarez, 2020. "How Do Millennial Managers Lead Older Employees? The Philippine Workplace Experience," $\quad$ SAGE Open, , vol. 10(1), pages 21582440209 , March

[14].Lincoln, Y. S., \& Guba, E. G. (1985). Naturalistic inquiry. Newbury Park, CA: Sage Publications, Inc.

[15]. Tongco, M. D. C. (2007). Purposive Sampling as a Tool for Informant Selection. Ethnobotany Research \& Applications, 5, 147-158

[16].Saunders, B., Sim, J., Kingstone, T., Baker, S., Waterfield, J., Bartlam, B., Burroughs, H., \& Jinks, C. (2018). Saturation in qualitative research: exploring its conceptualization and operationalization. Quality \& quantity, 52(4), 1893-1907. https://doi.org/10.1007/s11135-017-0574-8

[17].Merriam, S. B. (1998). Qualitative research and case study applications in education. San Francisco: JosseyBass Publishers.

[18].Pangilinan, D., Juan, A. G., Pascual, M., Santos, M., and Simangan, R. (2019). Acquired Knowledge, Skills and Abilities of Graduates of Business Administration of Graduate Education of Neust. International Journal of Advanced Engineering, Management and Science, 5 (7), 467-470, https://dx.doi.org/10.22161/ijaems.576

[19].Kapur, R. (2019). Development of Leadership Skills among Students. Retrieved online https://www.researchgate.net/publication/334988196_Development_of_Leadership_Skills_among_Students 